In some cases there has been more or less of vesical irritation for a few days before the acute attack, but in must instances the onset has been sudden and severe. The chief symptoms are frequent micturition, with more or less of uneasiness or pain in the region of the bladder. The calls to pass urine may occur every half-hour, or even oftener; and micturition is usually attended with an increase of pain and a sense of scalding in the neck of the bladder. The vesical irritation is increased by exercise, by exposure to cold, and by alcoholic liquors. The urine quickly becomes turbid with puriform mucus, and often blood-tinged. In one case there was a puriform discharge from the urethra as well as from the bladder, though the disease was certainly not the result of gonorrhœa. Usually the urine has an acid reaction; but, if there be much admixture of blood, the acidity is lessened by the alkali of the blood. It contains an abundance of albumen, partly derived from the puriform secretion, partly from the blood. On a microscopic examination, pus-cells and blood-corpuscles are seen in abundance, but no tube-casts. Although the local symptoms are distressing, there is little or no constitutional disturbance. The nights are disturbed by frequent calls to micturate, and the broken rest is attended with a sense of fatigue and nervous exhaustion ; but there is little fever, and no vomiting. If, within a few days from the onset of the symptoms, the patient be subjected to appropriate treatment, the disease usually subsides as rapidly as it came on. If, on the other hand, the symptoms be negligently or erroneously treated, the disease may become chronic, and cause prolonged and severe suffering. The urine becomes alkaline, ammoniacal, and foetid; there are perpetual pain and annoyance; and ultimately the disease may extend backwards through the ureters to the kidneys, and so set up a fatal pyelo-nephritis.

Diagnosis. - The distinction between acute cystitis and acute Bright's disease is sufficiently obvious if you bear in mind that the local symp. toms are all referable to the bladder, while dropsy, vomiting, and other renal symptoms, are absent. The urine is usually secreted in normal quantity, and of normal specific gravity. It is albuminous only in direct proportion to the amount of blood and pus which it contains, and the most careful microscopic examination discovers no tube-casts.

Treatment of Acute Cystitis. - In the treatment of this form of cystitis, you have to bear in mind that the inflammation of the lining membrane of the bladder is kept up and increased by contact of the acid and irritating urine. The main object of treatment is to diminish as much as possible the irritating qualities of the urine; with this object in view, the patient must be confined to bed or to a sofa in a warm room, and be kept on liquid food without stimulants. If there be no special reason in the peculiarity of the patient's stomach to forbid it, milk, cold or tepid, may serve as meat and drink-as a rule, milk is easily digested, and, at the same time, it acts as a diluent. If milk disagree, soup, beef-tea, mutton- or chicken-broth may be given, with the addition of some farinaceous pudding, and any simple diluent drink. Pure cold water is as efficacious, through not so pleasant, as aërated or Seltzer water. In addition, the urine is to be kept neutralised by citrate of potash, given every six hours. A warm hip-bath should be given night and morning; a dose of morphia at bedtime, to allay irritation and procure sleep; and an occasional seidlitz powder as a laxative if necessary. Under this plan of treatment, the acute symptoms usually subside with great rapidity; the pain and irritation pass away, and the urine regains its normal characters. After a few days, the citrate of potash may be discontinued, and the tincture of perchloride of iron given in twenty minim doses two or three times a day after food. So long as any mucus appears in the urine, even though the local uneasiness may have passed away, the patient should be kept under observation and treatment. If a chronic catarrhal condition of bladder remain after the acute symptoms have subsided, copaiba balsam often effects a rapid and complete cure. One capsule may be given an hour or two after food three times a day ; and, if the stomach will bear it, the dose may be increased until six and even nine capsules are taken in three doses in the twenty-four hours. In one case which had been of a year's duration, the urine being turbid with blood and pus, and smaller doses of copaiba having failed to cure, at the suggestion of Sir William Fergusson, who saw. the patient with me, the dose was increased to three capsules three times a day, and the result was a complete and permanent cure within six weeks; the urine at the end of the treatment being of natural sherry colour, transparent, and without a trace of mucus. Quite recently I have seen a young lady in whom acute cystitis from cold had left a vesical catarrh after a period of six weeks. I prescribed one capsule three times a day, and, in less than a week, the urine was entirely free from mucus, and the cure was complete. I have seen equally good results in other cases. It is probable that the remedy, being excreted by the kidneys, has a local curative action on the mucous mem brane of the bladder. The copaiba sometimes brings out a transient erythematous rash.

\section{CLINICAL LECTURE \\ ON A CASE OF}

\section{PARALYSIS OF THE DIAPHRAGM.}

\author{
BY C. HANDFIELD JONES, M.B.Cantab., F.R.S.,
} Physician to St. Mary's Hospital.

CASE.-E. H., aged 30, servant, was admitted January $14^{\text {th, }} 1873$. He had dark hair, and was of medium height, fairly well made. He had been ill, off and on, seven or eight years. When admitted, he had been ailing two months. He was very subject to headaches. He had had several severe falls, the first six years ago; he was insensible after the last for an hour, not after the previous ones. His father had hæmoptysis, and died four years ago, much emaciated; a sister laad no hæmoptysis, but was affected like the father. The patient had had hæmoptysis himself. He was not anæmic. His aspect was distressed. Pulse 80, regular, steady. There was great hyperæsthesia of the surface ; a cold hand applied made him start. The apex-beat of the heart was in the fifth left intercostal space, within or at the vertical nippleline. The area of cardiac dulness was not increased. No bruits were heard with the heart's sounds; they were very weak at the midsternum, more distinct at the apex. The rhythm was quite regular. The first sound was of good length at the apex. There was no murmur at the xiphoid cartilage. The jugulars were not full. The upper ribs moved considerably, and the whole chest was drawn upwards in inspiration; the lower ribs expanded very little; the abdomen scarcely moved at all. There was good percussion all over the front of the chest. Air entered freely in both lungs in front during deep inspira. tion. The breath-sounds were rather harsh. Resonance was fairly good throughout the back, and air was heard entering the lungs fairly well. He complained of shortness of breath, of inability to lie down, and of being put out of breath by the least exertion. He had not had an hour's sleep at night for two months; he dozed a little towards morning. He complained very much of aching and shooting pain in the left side, which, as well as the dyspnoea, prevented his sleeping. There was no cough or expectoration, nor any swelling of the legs. He had no appetite, and was thirsty, Hewas ordered to have simple diet, beef-tea and milk; and to take twenty grains of saccharated carbonate of iron three times a day, and to have ten grains of chloral hydrate at bedtime, to be repeated if necessary. On the 15 th, he had slept from 12 to 2 in the night, and again this morning. He was almost free from pain in the left side when visited, but had it badly a short time since. He had much headache and vertigo. He passed urine with difficulty and pain ; he said that he had not passed any till to-day since the 12th. The urine was full-coloured, pretty clear, of specific gravity I030, not albuminous. Pulse 64 ; temperature 100. - January 16th. He slept five hours last night, and felt better. The left side was tender when I percussed over it. There was no movement over the abdomen; the upper ribs played too much. The chloral was repeated, and he was ordered to have the following draught three times a day. Bo Ammonix carbon. gr. iv ; ferri ammonio-citratis gr. viii ; tincturæ nucis vomicæ $m x$; tincturæ calumbæ $m x$; aquæ $3 i$. - January 17 th. He had slept very well last night. Tongue clean. He had no pain in the side now . at all. Temperature 98.6. - January 18th. The bowels had been freely opened; much fæcal matter being brought away, with much relief. He had a good night without chloral, and felt better than he had done for two or three years. - January 2oth. He slept well, and felt much better. The abdomen at the upper part fell in ten divisions of Dr. Sibson's stethometer in deep inspiration. -January 24th. The breathing now was quite normal. The abdomen while he was recumbent rose fully in inspiration, and fell in expiration; this was the case with the upper part, which a few days before fell in during inspiration. The upper ribs moved a little-not more than normal. - February 6th. He had been an out-patient ten or twelve days, and was going on very well. Pulse steady and good, 80 . The upper ribs in the recumbent posture moved slightly; the lower more; the abdomen still more. A trace taken January 17 th was tolerably normal. The rise was low, and rather sloped ; the apex bluntish ; the descent long and gradual, with one well marked notch, and several minute ones.

Remarks. - The symptoms in this case were by no means plain to read-at any rate, at first. Subsequently, and chiefly by observation of the effects of remedies, they became more intelligible ; and, on retro- 
spect, the pathological story comes out sufficiently clear. The phenomena observed were, of a positive kind, dyspnœa, orthopnœa, incapacity for exertion, insomnia, left-side pain, altered respiratory movements, paresis of the diaphragm ; of a negative kind, healthy state of the lungs, heart, and kidneys, and of the vascular system generally. The family history pointed to the probable existence of the tuberculous diathesis in our patient, and his personal suggested the possibility of traumatic lesion of his brain or cord.

The chief symptom, around which several of the others grouped themselves, was the singular paresis of the diaphragm; and to this. therefore, our attention was specially directed. As a male, he ought to have used his diaphragm very much in breathing; and therefore the inaction of this great muscle was even more significant than it would have been in a female. Such inaction has been observed in empyema and in peritonitis, in advanced cases of progressive muscular atrophy, in sufferers from plumbic toxæmia, and in the hysterical (so called). It has not been observed, but might be presumed, to exist in cases of fatty degeneration of the diaphragm. A little reflection will enable us, looking back, to exclude all these conditions as being in any way concerned in our patient's trouble. There was no sign of pleurisy or peritonitis, of lead-poisoning, or of muscular atrophy : while the result excludes, I suppose, the possibility of fatty degeneration. Nevertheless, I must say I had some suspicions for a while that this morbid change might lie at the root of the matter; and these were not entirely dissipated until the efficacy of the remedies was clearly pronounced. $\mathrm{Mr}$. Callender (Lancet, 1867, Jan. 12) has recorded six cases of fatty degeneration of the diaphragm, but they were all complicated with a similar state of the heart ; and it does not appear that the state of the diaphragm had attracted attention during life, so that we cannot affirm whether it was paralysed or not.

It remains, therefore, to be considered, whether the symptom in question was a nervous phenomenon-was, in fact, a paralysis of the phrenic nerves. Two possibilities present themselves here-one, that there was actual lesion of the nerve-centres; the other, that the disorder was a paralytic neurosis. The falls which he had undergone-one of them from a great height-might well have injured his cord ; but the absence of any paralysis of the limbs or sphincters was an insuperable argument against this view. Had his cord been contused by a fall, the injury could not possibly have been confined to the nerve-cells connected with the phrenic nerve. The second view, therefore, seems the only one admissible. It was corroborated to some extent by the existence of left-side pain, which is extremely common in neurolytic conditions both in males and females, and by the presence also of general hyperesthesia, and, as it would seem, of spasmodic stricture. The result of treatment was very positive, and leaves no doubt in my mind that no organic lesion existed, and that we had only to deal with a rare variety of neurotic disorder. As I mentioned before that palsy of the diaphragm was met with amongst the hysterical, you will perhaps expect that I should so designate the neurotic paralysis in our case ; but I decline to do so, because the patient presented none of the recognised features of hysteria. He had had, so far as we know, no globus, or fits, or aphonia, or dysphagia, or paraplegia. There was no varying or shifting of his troubles from one part to another ; no tendency to exaggeration or deception-nothing, in fact, to distinguish him from any bon $\hat{\alpha}$ fide sufferer. His aspect was distressed, and quite unlike that of some invalids, who assure you with calm countenance that they are suffering "agonies of pain". I pass by the slight difficulty that our patient did not possess an uterus, and so could not legitimately be reckoned an $\boldsymbol{v} \sigma \tau \epsilon \rho$ өкos. Let me strongly advise you to reserve a place in your minds for the idea of functional paralysis, either depending on remote irritation, or on toxæmia, or simple exhaustion ; and to abstain from applying loosely the term "hysterical". It were better, I think, laid aside altogether, as it will, I suspect, always carry with it a savour of more or less suspicion that the disorder is not genuine, not physical, but more or less consciously simulated. In very many instances this suspicion is unjust, in others it is well founded.

I regard, then, our patient as having suffered from some cause which does not appear a functional paralysis of the centres belonging to his phrenic nerves. Possibly he has an infirm constitution of his nervous system. The hereditary tendency to tuberculosis which he evidently had may have become converted into this other deterioration. It does not seem very clear why aphonia should be reckoned a necessary symptom of palsy of the diaphragm, as has been somewhat too broadly stated. The diaphragm is not an expiratory muscle; and, if a tolerable amount of air be inspired by the other muscles, sufficient to aerrate the blood, it seems probable that quite a sufficient current would traverse the glottis during expiration to produce sounds. In fact, it does not appear that the aphonia is at all complete: the patients can speak, but arc sooner or later obliged to desist for lack of breath. Eulenburg says the voice becomes weak, but phonation itself does not suffer. This was the case in our patient, and seems to have been so in the case which Eulenburg relates. In Bazire's case (vide BRITISH MEDICAL JOURNAL, 1867, vol. i, p. 597), laryngoscopic examination detected nothing abnormal about the glottis. The vocal cords approximated normally when she uttered a sound. This, however, is scarcely sufficient to prove that the same effort could be maintained for any continuance. It seems rather surprising that disorders of the diaphragm are not more frequent, considering the long course of the phrenic nerves, and their great liability to be pressed on by enlarged glands or indurated exudation-masses in some part of their course. Dr. Bazire well observes that the results obtained by galvanising (faradising) the phrenic nerves will at once indicate whether the palsy is due to a structural alteration, or is merely functional. In the latter case, the muscle will contract powerfully when its nerves are stimulated; in the former, it will respond feebly or not at all. Duchenne was the first to show that paralysis of the diaphragm is not of itself fatal, as had previously been thought; but he observes that, though the patient may survive long, his condition is perilous, inasmuch as a slight bronchitis may induce fatal asphyxia.

A remarkable symptom in Duchenne's patient was, that forced inspiratory efforts, instead of satisfying the want of air which she felt, greatly increased her distress. She expressed very well what she felt at such times by saying that her bowels suffocated her by rising up into her chest. In Bazire's case, however, no such sensation was ever felt ; nor was it complained of by E. H., nor is it noticed by Eulenburg in the case he relates. In all these patients, the causation was obscure. The last had certainly been chilled, and got a stiff neck nine days before the paralysis came on; but it seems very doubtful whether this had anything to do with the latter.

In the way of treatment, localised faradisation of the phrenic nerves is advised by Duchenne de Boulogne, and proved strikingly effectual in Eulenburg's case ; in Bazire's, it failed ; in my own, it was not employed, as the tonics and sedative were so speedily successful. Whatever be the cause of the paralysis, faradic stimulation of the muscle and its nerves seems desirable, although other treatment may be varied according to the special features of the case. Even in the advanced stage of progressive muscular atrophy, faradisation has proved successful in saving the diaphragm.

\section{CONVULSIONS TREATED BY THE INHALATION OF CHLOROFORM.*}

By GEORGE MOWAT, Esq., Swansea.

I am glad to have the opportunity of laying the notes of two cases of convulsions, treated by the inhalation of chloroform, before the members of this Branch-not that the treatment is by any means original, but because the satisfactory results have made such an impression upon me, that I cannot but believe we have a remedy in chluroform which is likely to supersede the old remedies which we have been accustomed to use. I can call to mind a large number of cases treated by the warm bath, cold to the head, calomel purges, small doses of calomel frequently repeated, bromide of potassium, etc., the results in which have been anxiously tardy when successful, and in not a few of which death has resulted. I think that in chloroform we have a remedy which will check the fit and give time for after-treatment in all cases where the origin of the attack is sympathetic, reflex, or eccentric; but I should be very cautious in applying such treatment to a case of convulsions occurring during the progress of disease of the brain, for instance. Some years ago I was much struck by the successful treatment of a case of traumatic tetanus, which occurred in the practice of Mr. Parsons of Bridgewater, in which the effect of chloroform was kept up for thirtysix hours or more. I should certainly try its effects in those bad cases of chorea in which the patients do injury to themselves from the violence of the movements, which also prevent sleep.

Dr. Ringer, in his book on Therapeutics, says : "Fits of convulsions, especially in children, can be stayed by chloroform ; and when they have been prolonged, and exhaustion has been threatened, the child in some cases has been brought from a state of great danger to one of safety, the convulsion being quite stayed, and consciousness restored by the inhalation of chloroform."

Dr. Churchill, in his book on Diseases of Chillren, quotes a " case of convulsions, complicating whooping-cough, where he used it with benefit; and one in which Sir James Simpson used it with perfect suc.

* Read before the South Wales and Monmouthshire Branch. 